\title{
A male with type I orofaciodigital syndrome
}

\author{
J Goodship, J Platt, R Smith, J Burn
}

\begin{abstract}
We describe a three generation family with three females showing minor features of orofaciodigital syndrome type I and a severely affected male in the third generation. In addition to the classical features of OFD I, the male had bilateral duplication of the halluces, a feature diagnostic of OFD II, and an atrioventricular septal defect. Heart defects have not previously been reported in OFD I but have been reported in OFD II. It is important to examine the mothers of all male neonates with orofaciodigital syndrome with care before making a diagnosis of OFD II.
\end{abstract}

In 1954 Papillon-Leage and Psaume described eight girls with a syndrome involving median clefts of the upper lip, oral frenulae, a lobulated tongue, and asymmetrical shortening of the digits. ${ }^{1}$ This was followed by numerous reports of affected females. Female to female transmission was observed. Gorlin et $a l^{2}$ suggested that orofaciodigital syndrome is an $\mathrm{X}$ linked dominant condition lethal in males, though sex limited autosomal dominant inheritance cannot be excluded.

Between 1954 and 1967 all affected subjects reported were female with the exception of two phenotypic males who were both found to have 47 chromosomes on blood karyotype. They were described before the advent of chromosome banding techniques. In the first case the extra chromosome was simply assigned to group $\mathrm{A}^{3}$ and in the second

Regional Genetics Advisory Service, 19 Claremont Place, Newcastle upon Tyne NE2 4AA.

J Goodship, J Platt, R Smith, J Burn

Correspondence to Dr Goodship.

Received for publication 20 November 1990 Accepted for publication 2 January 1991. case it was known to be an $\mathrm{X}$ chromosome. ${ }^{4}$ In retrospect both of these infants had Klinefelter's syndrome in addition to OFD.

In 1967 Rimoin and Edgerton ${ }^{5}$ reported a girl and two male sibs with the features of orofaciodigital syndrome. The first affected male in this family was stillborn and the second was an 18 year old college student. Both parents were normal. They recommended that the dominant condition should be designated OFD I and the autosomal recessive condition OFD II or Mohr syndrome. In $1941 \mathrm{Mohr}^{6}$ described a sibship with two affected males who died at 6 months and 1 day of age and a third, severely retarded, affected surviving male aged 8 months. It is interesting to note that when $\mathrm{Mohr}^{6}$ first described this family he suggested that the condition was $\mathrm{X}$ linked and sublethal in males. Claussen ${ }^{7}$ extended the pedigree five years later finding another boy with polydactyly and malformations of the tongue and suggested an autosomal recessive inheritance pattern.

There is considerable overlap between the findings in the two syndromes. We describe three females with minor features in two generations, one of whom gave birth to a severely affected male. The pedigree is shown in fig 1 . Without careful examination of the females in this family, the child would have been classified as OFD II and incorrect counselling given.

\section{Case report}

The proband was referred with her husband to the fetal assessment clinic after intracranial and cardiac abnormalities were detected on a routine fetal ultrasound scan carried out at 18 weeks' gestation. Fetal echography indicated hydrocephalus, absent corpus callosum, and a large posterior fossa cyst (fig 2) and an isolated atrioventricular septal defect.

On examination the proband had a minor pseudocleft of the upper lip, lobulated tongue tip, multiple frenulae of the lower lip (fig 3), and short fifth 


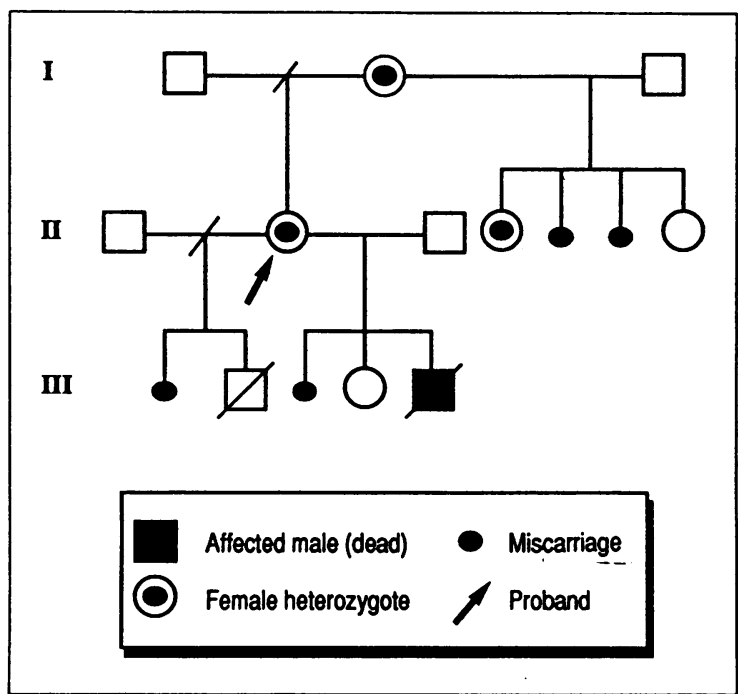

Figure 1 Family pedigree.

metacarpals. She had had two first trimester miscarriages, a son who died of sudden infant death syndrome at 5 months of age, and a normal 3 year old daughter. Her mother and one sister were also found to have a lobulated tongue and alveolar frenulae. Subsequent computed tomography did not show intracranial pathology in the three affected females.

The couple were counselled that the most likely underlying cause was OFD I. They elected to continue the pregnancy and spontaneous labour occurred at 34 weeks' gestation.

A male infant was delivered by caesarian section. On examination he had a midline pseudocleft of the upper lip, a cleft soft palate, hypertelorism, bifid

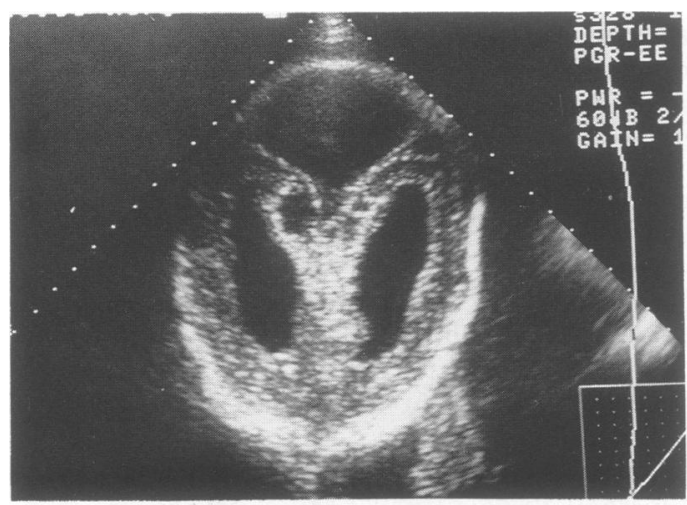

Figure 2 Cranial ultrasound at 19 weeks' gestation. There is a moderate degree of ventricular dilatation associated with a cystic cavity in the posterior fossa which extended rostrally in the midline. halluces with varus deformity, postaxial accessory digits on both hands, a bifid fifth toe on the right foot, and normal male genitalia. The baby rapidly developed cardiac failure and died 21 hours after delivery. The scan findings were confirmed at necropsy. In addition, brain examination showed polymicrogyria. The karyotype was $46, \mathrm{XY}$.

\section{Discussion}

There is considerable overlap between the findings in OFD I and OFD II (table). Pseudocleft of the upper lip, tongue lobulation, hamartomata on the tongue, alveolar frenulae, and clefting of the soft palate are common to both conditions. It has been reported that aplasia of the lateral incisors is found in OFD I, while aplasia of the central incisors is a feature of OFD II. ${ }^{5}$ Alopecia and milia have been reported only in type I. Abnormalities of hands and feet are found in both conditions. While brachydactyly and polydactyly are recognised features of both conditions, bilateral duplication of the hallux has been regarded as a cardinal feature of OFD II. ${ }^{589} \mathrm{It}$ has been suggested that radiological features may distinguish between the two with irregular mineralisation of the hands and feet being pathognomonic of OFD $I^{10}$ Intracranial abnormalities have been reported in both conditions. ${ }^{11-14}$ Polycystic kidneys have been reported in some patients with OFD $I^{15-17}$ but not in any patients with OFD II. The brother and sister described by Rimoin and Edgerton ${ }^{5}$ both had sensorineural hearing loss. This is not a feature of OFD I, though it has not been reported in any further cases of OFD II either, with the exception of one case where the deafness was attributed to brainstem compression. ${ }^{14}$

Rimoin and Edgerton ${ }^{5}$ suggested that the cardinal feature of OFD II is bilateral polysyndactyly of the halluces. However, the male in the family we describe here had bilateral polysyndactyly of the halluces. Recently another family has been described with five affected males in three generations with transmission through females. ${ }^{18}$ The males were severely affected, with three of them dying in infancy, while the features in the two obligate female carriers examined were very minor. There was bilateral polysyndactyly in all five of the affected males in this family, though this was not present in either of the two females examined. In addition, there have been several reports of girls who have all of the clinical features thought to be specific to OFD I, including the milia and sparse hair, but no family history, who have also had bilateral polysyndactyly of the halluces. ${ }^{101920}$ It is also interesting to note that one of the trisomic males reported ${ }^{3}$ had bilateral polysyndactyly of the halluces and the other ${ }^{4}$ had right sided polysyndactyly of the hallux. Clearly a 

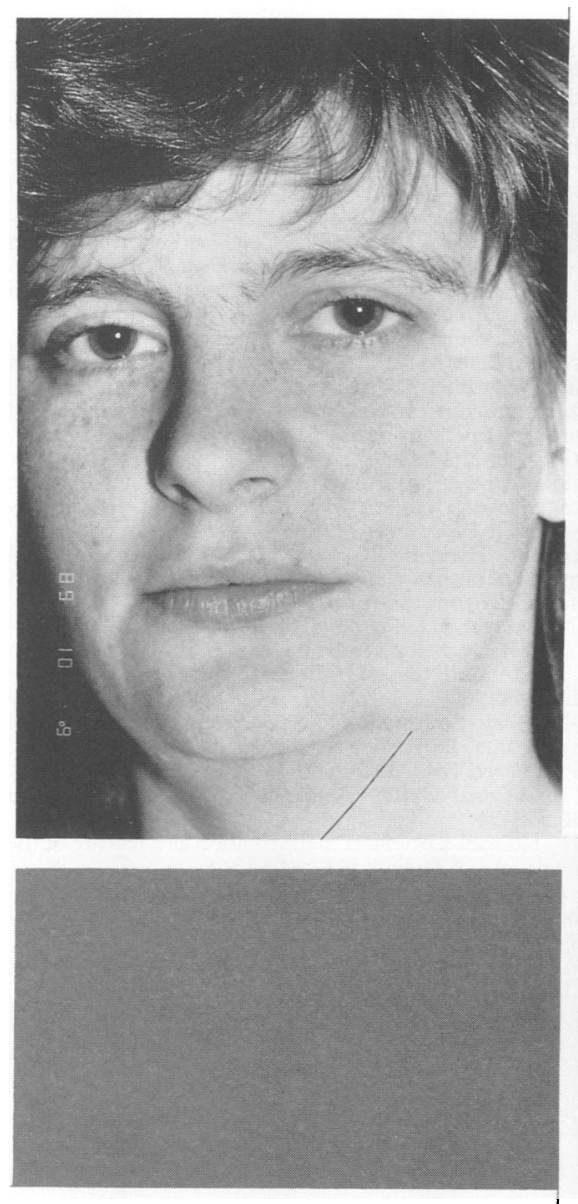

Figure 3 Photographs of the proband showing the bifid tongue tip, thinning of the upper lip, and the alveolar frenulae.

Clinical features of OFD I and OFD II.

\begin{tabular}{|c|c|c|}
\hline & OFD I & OFD II \\
\hline $\begin{array}{l}\text { Pseudocleft upper lip } \\
\text { Lobulated tongue } \\
\text { Tongue nodules } \\
\text { Alveolar frenulae } \\
\text { Cleft palate }\end{array}$ & $\begin{array}{l}+ \\
+ \\
+ \\
+ \\
+\end{array}$ & $\begin{array}{l}+ \\
+ \\
+ \\
+ \\
+\end{array}$ \\
\hline $\begin{array}{l}\text { Aplasia of lateral incisors } \\
\text { Aplasia of central } \\
\text { incisors }\end{array}$ & $\begin{array}{l}+ \\
-\end{array}$ & $\begin{array}{l}- \\
+\end{array}$ \\
\hline Alopecia and milia & + & - \\
\hline $\begin{array}{l}\text { Brachydactyly, } \\
\text { polydactyly } \\
\text { Duplicated hallux }\end{array}$ & $\stackrel{+}{+}$ Unilateral & $\stackrel{+}{\text { Bilateral }}$ \\
\hline $\begin{array}{l}\text { Intracranial } \\
\quad \text { abnormalities } \\
\text { Polycystic kidneys } \\
\text { Heart defect } \\
\text { Deafness } \\
\text { Radiology }\end{array}$ & $\begin{array}{l}+ \\
+ \\
+ \\
- \\
\text { Irregular reticular } \\
\text { areas, short } \\
\text { tubular bones }\end{array}$ & 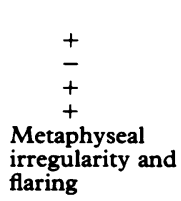 \\
\hline
\end{tabular}

diagnosis of OFD II cannot be made on the basis of bilateral polysyndactyly of the halluces.

Congenital heart defects have been reported in two families with OFD II but have not previously been observed in OFD I. The first case was a female who, on necropsy, was found to have a common atrium, a single atrioventricular valve, single ventricle, and truncus arteriosus. ${ }^{21}$ In the second report a male infant with classical features of OFD and a ventricular septal defect died a few days after birth. ${ }^{22}$ In the woman's second pregnancy ultrasound scans showed that this fetus also had a heart malformation. At term she delivered a female infant with OFD. The child died a few days after birth and at necropsy an atrioventricular septal defect was found. The male described here shows that congenital heart defects are not confined to OFD II.

OFD I and OFD II are not phenotypically distinct and the case against an autosomal recessive locus $^{2023}$ deserves re-examination. When a male neonate has features of orofaciodigital syndrome it is 
important to examine his mother carefully and not to assume that he has OFD II. In the family presented here and in the family described by Edwards et al, ${ }^{18}$ the clinical features in the affected females were minor and would have been missed without thorough examination. If male survival in orofaciodigital syndrome is a reflection of allelic variation at an $\mathrm{X}$ chromosome locus it is to be expected that heterozygous females will have minor features when hemizygous males survive.

We wish to thank our colleagues, Dr P Rose and Professor T Lind, in the fetal assessment clinic.

1 Papillon-Leage M, Psaume J. Une malformation hereditaire de la muqueuse buccale, brides et freins anormaux: generalites. Rev Stomatol 1954;55:209-27.

2 Gorlin RJ, Anderson VE, Scott CR. Hypertrophied frenuli, oligophrenia, familial trembling and anomalies of the hand. N Engl f Med 1961;264:486-9.

3 Kushnick T, Massa TP, Baukema R. Orofaciodigital syndrome in a male. $\mathcal{F}$ Pediatr 1963;63:1130-4.

4 Wahrman J, Berant M, Jacobs J, Aviad I, Ben-Hur N. The oral-facial-digital syndrome: a male-lethal condition in a boy with 47/XXY chromosomes. Pediatrics 1966;37:812-21.

5 Rimoin DL, Edgerton MT. Genetic and clinical heterogeneity in the oral-facial-digital syndromes. $f$ Pediatr 1967;71:94102.

6 Mohr OL. A hereditary sublethal syndrome in man. Norske Videnskab Akad Mat Naturv Klasse 1941;4:1-18.

7 Claussen $\mathrm{O}$. Et arvelig syndrom omfattende tungemisdannelse og polydaktyli. Nord Med 1946;30:1147-51.

8 Fuhrmann W, Stahl A. Differential diagnose von PapillonLeage-Psaume-syndrom und Mohr-syndrom. Humangenetik 1970;9:54-63.
9 Ajacques JC. Le syndrom de Mohr. Rev Stomatol Chir Maxillofac 1981;82:234-40.

10 Anneren G, Arvidson B, Gustavson KH, Jorulf H, Carlsson G. Oro-facio-digital syndromes I and II: radiological methods for diagnosis and the clinical variations. Clin Genet 1984;26:178-86.

11 Towfighi J, Berlin CM, Ladda RL, Frauenhoffer EE Lehman 'RAW. Neuropathology of oral-facial-digital syndromes. Arch Pathol Lab Med 1985;109:642-6.

12 Wood BP, Young LW, Townes PL. Cerebral abnormalities in the oral-facial-digital syndrome. Pediatr Radiol 1975;3:130-6.

13 Haumont D, Pelc S. The Mohr syndrome: are there two variants? Clin Genet 1983;24:41-6.

14 Reardon W, Harbord MG, Hall-Craggs MA, Kendall B, Brett EM, Baraitser M. Central nervous system malformations in Mohr's syndrome. $f$ Med Genet 1990;99:659-63.

15 Donnai D, Kerzin-Storrar L, Harris R. Familial orofaciodigital syndrome type I presenting as adult polycystic kidney disease. F Med Genet 1987;24:84-7.

16 Harrod MJE, Stokes J, Peede LF, Goldstein JL. Polycystic kidney disease in a patient with the oral-facial-digital syndrome - type I. Clin Genet 1976;9:183-6.

17 Connacher AA, Forsyth CC, Stewart WK. Orofaciodigital syndrome type I associated with polycystic kidneys and agenesis of the corpus callosum. F Med Genet 1987;24:116-22.

18 Edwards M, Mulcahy D, Turner G. X-linked recessive inheritance of an orofaciodigital syndrome with partial expression in females and survival of affected males. Clin Genet 1988;34:325-32.

19 Fenton OM, Watt-Smith SR. The spectrum of the oro-facial digital syndrome. Br $\mathcal{F}$ Plast Surg 1985;38:532-9.

20 Townes PL, Wood BP, McDonald JV. Further heterogeneity of the oral-facial-digital syndromes. $A m$ f Dis Child 1976;130:548-54.

21 Cordero JF, Holmes LB. Heart malformation as a feature of the Mohr syndrome. f Pediatr 1977;91:683-4.

22 Iaccarino M, Lonardo F, Giugliano M, Della Bruna M. Prenatal diagnosis of Mohr syndrome by ultrasonography. Prenat Diagn 1985;5:415-18.

23 Whelan DT, Feldman W, Dost I. The oro-facial-digital syndrome. Clin Genet 1975;8:205-12. 